\title{
Tensile and fracture mechanical properties of styrene-butadiene rubbers (SBR) filled with industrial and pyrolytic carbon blacks, and organoclay
}

\author{
Péter BERKI1,a , József KARGER-KOCSIS ${ }^{1,2, b^{*}}$ \\ ${ }^{1}$ Department of Polymer Engineering, Faculty of Mechanical Engineering, Budapest University of \\ Technology and Economics, H-1111 Budapest, Múegyetem rkp. 3, Hungary \\ ${ }^{2}$ MTA-BME Research Group for Composite Science and Technology, H-1111 Budapest, \\ Müegyetem rkp. 3, Hungary \\ aberki@pt.bme.hu, bkarger@pt.bme.hu
}

\begin{abstract}
Keywords: organoclay (I30.P), styrene-butadiene rubber (SBR), carbon black (CB), pyrolytic carbon black $(\mathrm{pCB})$, mechanical properties, Payne-effect, Mullins-effect, J-integral, crack tip opening (CTOD)
\end{abstract}

\begin{abstract}
In this work we examined effects of filler combinations (industrial carbon black (CB), pelletized pyrolytic carbon black $\left(\mathrm{pCB}_{\mathrm{p}}\right)$ and organoclay $(\mathrm{I} 30 . \mathrm{P})$ on the tensile mechanical and fracture mechanical properties of SBR rubbers. The performance of standard N660 CB was compared with that of $\mathrm{pCB}_{\mathrm{p}}$ when used alone or in 1: 1 blend ratio at an overall filler content of 60 part per hundred part rubber (phr). The study covered also a mix composed of $20 \mathrm{phr} \mathrm{pCB}, 20 \mathrm{phr}$ N660 and 10 phr I30.P the hardness of which was identical to those of the (p)CB filled ones. N660 yielded better tensile properties than $\mathrm{pCB}_{\mathrm{p}}$. By contrast, the latter yielded higher tear and trouser tear strength values than CB. I30.P increased the storage modulus value (E') in spite of the filler content of $50 \mathrm{phr}$. Presence of organoclay and $\mathrm{pCB}_{\mathrm{p}}$ also increased the critical value of the Jintegral.
\end{abstract}

\section{Introduction}

Disposal and recycling of the increasing amount of waste tires are great challenges nowadays. Intensive research is addressing various aspects of tire recycling [1-2]. Today, worn tires are commonly used for energy generation, but value-added material-related options are in forefront of interest. For example, ground tire rubber (GTR) can be minor or major component in thermoplastic elastomers [2]. Another possibility is the partial devulcanization, after which the devulcanized, reclaimed rubber can be used, mostly as additive, again. For devulcanization ultrasonic and microwave techniques are most promising [2-3]. Pyrolytic processes produce a carbonaceous solid and a volatile fraction. The latter is a common feedstock of the pyrolysis itself $[1,4]$. The pyrolytic carbon black (pCB) may well be used as rubber reinforcement [5-7]. pCB contains inorganic materials from the initial rubber recipe $\left(\mathrm{CaCO}_{3}, \mathrm{ZnO}, \mathrm{SiO}_{2}\right)$ based on which it has a dual character [6]. The quality of the resulting carbon black depends on the "feedstock" (rubber recipe) and production conditions (temperature, pressure, atmosphere) $[1,4,6]$, and on the post-treatment, as well. During oxygen-free pyrolysis the product has higher carbon content which when heat-treated at a high temperature may approach the quality of the commercial CBs. Additional acid treatment removes the residual minerals. These treatments are not always practical because some benefits of the dual structure (especially the silica content) are lost. According to Norris the guaranteed quality pCB is between N300-N700 standard CBs [6].

In our research we used a styrene-butadiene rubber (SBR) because it is one of the major component of tires' formulations. Two types of CBs, namely a standard N660 and a pelletized pyrolytic $\mathrm{CB}\left(\mathrm{pCB}_{\mathrm{p}}\right)$ were involved in this study. To check the application potential of $\mathrm{pCB}$, these $\mathrm{CBs}$ were used alone and 1: 1 blend ratio at a total filler content of $60 \mathrm{phr}$. Further aim was to examine the effect of additional organoclay. Previous studies have shown that the combination of organoclay and industrial CB may show excellent reinforcing effect in rubbers [8-9]. The I30.P organoclay was added in $10 \mathrm{phr}$. Learning from the literature is that rubber combinations having the 
same hardness should be produced for comparison purpose [10]. Since organoclay (I30.P) increases the hardness more strongly than $\mathrm{CB}$ (due to a larger specific surface weight) the overall filler content was reduced to $50 \mathrm{phr}$. So, the related SBR gum contained $20 \mathrm{phr}$ pCB, $20 \mathrm{phr}$ N660 and $10 \mathrm{phr}$ I30.P. The SBR compounds were tested to evaluate the mechanical properties (tensile strength, elongation at break, tear strength), dynamic mechanical properties (DMTA), the softening caused by cyclical and dynamic loading (Mullins effect, Payne effect [11]), and the quasi-static fracture mechanical properties. To determine the latter single edge-notched tensile (SEN-T) and trouser-shaped testpieces were used. For fracture mechanical characterization the J-integral and CTOD (crack tip opening displacement) methods were adopted. CTOD $=0.5 \mathrm{~mm}$ was chosen for the critical value.

\section{Experimental}

Materials, compounding The recipe used is given in Table 1. The rubber was mixed on a laboratory two roll mill (Labtech Scientific LRM-SC-110), friction was 1.3, the temperatures of the front and back rotors were $70^{\circ} \mathrm{C}$ and $50^{\circ} \mathrm{C}$, respectively. The time of mixing was $27 \mathrm{~min}$. The samples were cured in a Collin Teach-Line Platen Press $200 \mathrm{E}$ laboratory press at $160^{\circ} \mathrm{C}$ for the $\mathrm{t}_{0.9}$ time (time needed to reach $90 \%$ of cure in rheometer) of the compounds with $5 \mathrm{MPa}$ pressure producing sheets with $2 \mathrm{~mm}$ thickness. Curing studies were performed using MonTech Monsanto $\mathrm{R} 100 \mathrm{~S}$ rheometer, in the isothermal time sweep mode $\left(1.667 \mathrm{~Hz}, 1^{\circ}\right.$ angle $)$ for the samples at $\mathrm{T}=160^{\circ} \mathrm{C}$ for 45 minutes.

Table 1. Designation and composition of SBR mixes and the hardness values of rubbers.

Designation: MBTS-2-mercaptobenzothiazole

\begin{tabular}{|l|c|c|c|c|c|c|c|c|c|}
\hline \multirow{2}{*}{ Designation } & \multicolumn{7}{|c|}{ Composition [phr] } & \multirow{2}{*}{$\begin{array}{c}\text { Hardness } \\
{\left[\text { ShA }^{\circ}\right]}\end{array}$} \\
\cline { 2 - 11 } & SBR & I30.P & N660 & pCBp & ZnO & $\begin{array}{c}\text { Stearic } \\
\text { acid }\end{array}$ & MBTS & S & \\
\hline SBR ref. & 100 & - & - & - & 3 & 2 & 1.5 & 2 & $40 \pm 0$ \\
\hline I30.P & 100 & 10 & - & - & 3 & 2 & 1.5 & 2 & $50 \pm 1$ \\
\hline N660 & 100 & - & 60 & - & 3 & 2 & 1.5 & 2 & $67 \pm 1$ \\
\hline pCBp & 100 & - & - & 60 & 3 & 2 & 1.5 & 2 & $63 \pm 1$ \\
\hline N660+pCBp & 100 & - & 30 & 30 & 3 & 2 & 1.5 & 2 & $63 \pm 1$ \\
\hline N660+pCBp+I30.P & 100 & 10 & 20 & 20 & 3 & 2 & 1.5 & 2 & $65 \pm 1$ \\
\hline
\end{tabular}

Testing Specimens (DIN 53504 Type 1 for tensile and ASTM D624 Type C for tear tests) were punched from the sheets. Tensile (ISO 37) and tear tests (ISO 34-1) were performed on a Zwick Z250 universal testing machine with a crosshead speed of $500 \mathrm{~mm} / \mathrm{min}$ at room temperature. Each of above tests was repeated on five specimens to deduce the mean values. Strain softening (Mullins effect) was studied on the above dumbbell specimens, which were loaded sequentially to increasing strain levels, namely to 50,100, 150 and 200\%, respectively. After reaching the lower fixed strain, the specimen was fully unloaded before starting with its subsequent loading cycle up to the next, higher fixed, strain value. DMTA spectra were registered on rectangular specimens in tensile mode at a static preload $0.1 \mathrm{~N}$ with $0.1 \%$ strain. The frequency was $10 \mathrm{~Hz}$ and the spectra were taken in a temperature range of -100 to $60^{\circ} \mathrm{C}$ using a Q800 device of TA Instruments. The temperature ramp was $3^{\circ} \mathrm{C} /$ minute. DMTA technique was used to assess the Payne effect. It was investigated also in tensile mode, $0.01 \mathrm{~N}$ static preload, however, at $30{ }^{\circ} \mathrm{C}$ using $10 \mathrm{~Hz}$ frequency with a strain sweep from 0.01 to $10 \%$ strain. Fracture mechanical tests were performed on single edge-notched tensile loaded (SEN-T) and trouser tear specimens. SEN-T specimens of 100 × $25 \times 2 \mathrm{~mm}$ dimension (length $\mathrm{x}$ width $\mathrm{x}$ thickness) with $10 \mathrm{~mm}$ initial notch length were loaded with $10 \mathrm{~mm} / \mathrm{min}$ crosshead speed on the above mentioned Zwick testing machine. The crack tip opening displacement (CTOD) has been followed by visual inspection using a digital miscroscope. The camera was positioned in front of the crack in order to focus on the internal surface generated by 
blunting and growing of the crack. J-integral tests were also performed on specimens, which were loaded up to $100 \%$ deformation at $200 \mathrm{~mm} / \mathrm{min}$ crosshead speed in five cycles (to eliminate the Mullins effect) and notched afterward. The fracture energy from trouser tear $\left(\mathrm{J}_{\text {trouser }}\right)$ was determined on $100 \times 30 \times 2 \mathrm{~mm}$ specimens (length $\mathrm{x}$ width $\mathrm{x}$ thickness) with an initial notch length of $40 \mathrm{~mm}$ at $100 \mathrm{~mm} / \mathrm{min}$ deformation rate.

\section{Results and discussion}

Mechanical behavior The tensile strength and ultimate tensile elongation data are displayed in Figure 1. a. The test samples have same hardness, with the exception of the unfilled SBR and SBR with I30.P, because they serve as references. The maximum tensile strength with the lowest ultimate tensile strain delivered N660. In contrast, $\mathrm{pCB}_{\mathrm{p}}$ leads the lowest tensile strength and the largest deformability. This suggests that $\mathrm{pCB}_{\mathrm{p}}$ is a less active filler than $\mathrm{N660}$. As expected, the blend of $\mathrm{N} 660+$ pCBp yields intermediate results. The tensile performance of the gum with $\mathrm{N} 660+\mathrm{pCBp}+\mathrm{I} 30 . \mathrm{P}$ is slightly better than the mixture containing only $\mathrm{pCBp}$, although the filler level in this case in only $50 \mathrm{phr}$.

In Figures $1 . b$. the tear strength and trouser tear $\left(\mathrm{J}_{\text {trouser }}\right)$ data can be seen. $\mathrm{J}_{\text {trouser }}$ was determined by the Eq. 1 where ' $F_{\text {tear }}$ ' is the constant force after the onset of crack propagation, and ' $t$ ' is the thickness of the specimen.

$$
J_{\text {trouser }}=\frac{2 \cdot F_{\text {tear }}}{t}
$$
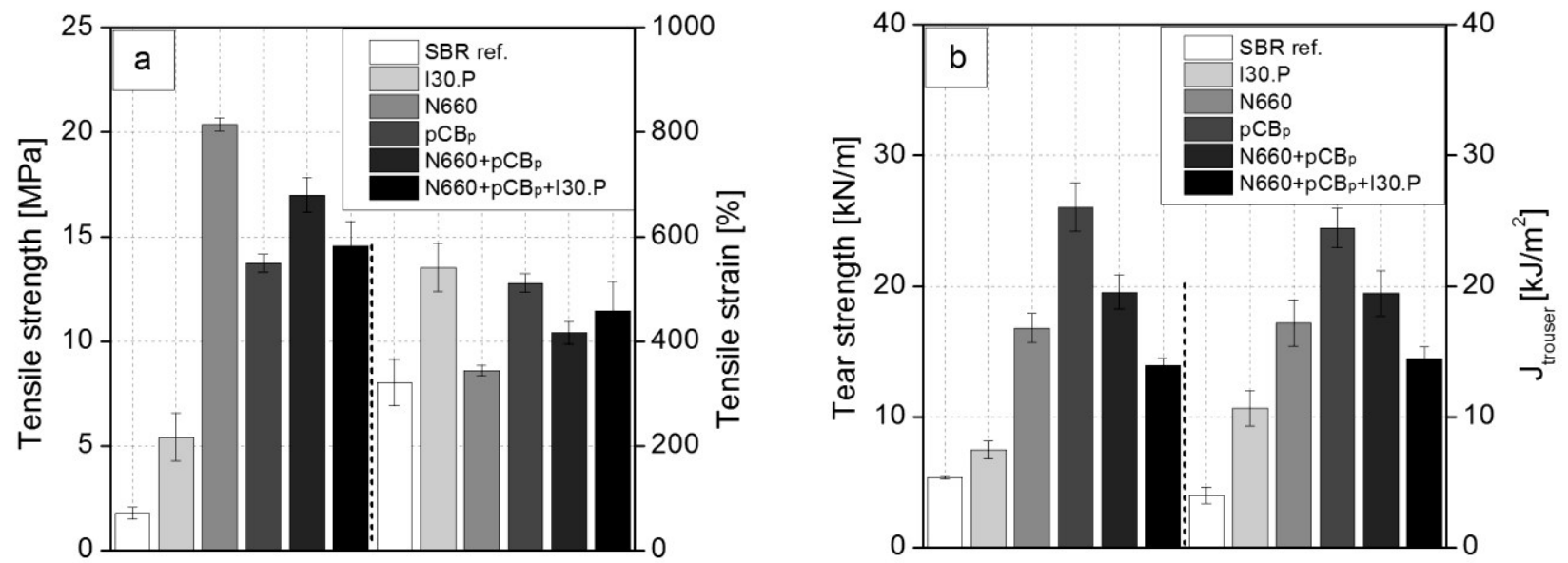

Figure 1. Mechanical and fracture mechanical properties of the SBR rubbers:

a.) Tensile strength and ultimate tensile strain data; $b$.) Tear strength and $\mathrm{J}_{\text {trouser }}$ values

It is striking that the highest tear values exhibit the $\mathrm{pCB}_{\mathrm{p}}$-containing mix. This positive effect occurs also in combination with N660 and also I30.P. This effect may be linked with the wide distribution of the $\mathrm{pCB}_{\mathrm{p}}$ particles. The large/small particles force the crack to follow a zigzag path associated with higher energy absorption. We expected good results from I30.P, because the layered structure of clay may further increase the crack propagation resistance. This effect was, however, not observed. Interesting observation is that there is a clear correlation between the various crack opening modes (tear strength - I mode, $\mathrm{J}_{\text {trouser }}$ - III. mode), the values are numerically very similar and their units are the same.

DMTA behavior, Payne-effect, Mullins-effect Figure 2. a. shows the DMTA results (loss factor and storage modulus). In terms of loss factor, a marginal change in the glass transition temperature $\left(\mathrm{T}_{\mathrm{g}}\right)$, read at the temperature linked to the maximum of the $\tan \delta$ peak, was found. Increasing reinforcement yields decreasing $\tan \delta$ peak value, because the segmental motion of the rubbers chains is hampered in the filler-rubber interphase. In this regard, the strongest rubber-filler 
interaction was found for the $\mathrm{N} 660+\mathrm{pCB}+\mathrm{p}+\mathrm{I30.P}$ sample, which is clearly attributable to the effect of I30.P. This mixture exhibits the highest E' in the rubbery range. Between the E' values of the other CB filled mixtures a negligible difference can be observed.

Figure 2. b. shows the evolution of the Payne effect. The E' of CB filled rubbers has significant amplitude dependence. Naturally, it is influenced by the filler activity: with increasing specific surface weight of $\mathrm{CB}$ the related Payne effect also increases. Note that the initial E' values of the $\mathrm{pCB}_{\mathrm{p}}$ containing samples were lower than those with N660. I30.P containing (p)CB filled rubber provides the highest E', and it shows the greatest Payne-effect, as well. According to Figure 2 the layered structure organoclay has significant effect on the dynamic properties. The application of I30.P leads to enhanced rigid filler-rubber interactions which cause increasing E' at low strains. However, this effect diminishes with increasing strain values due to damage of the filler "network".
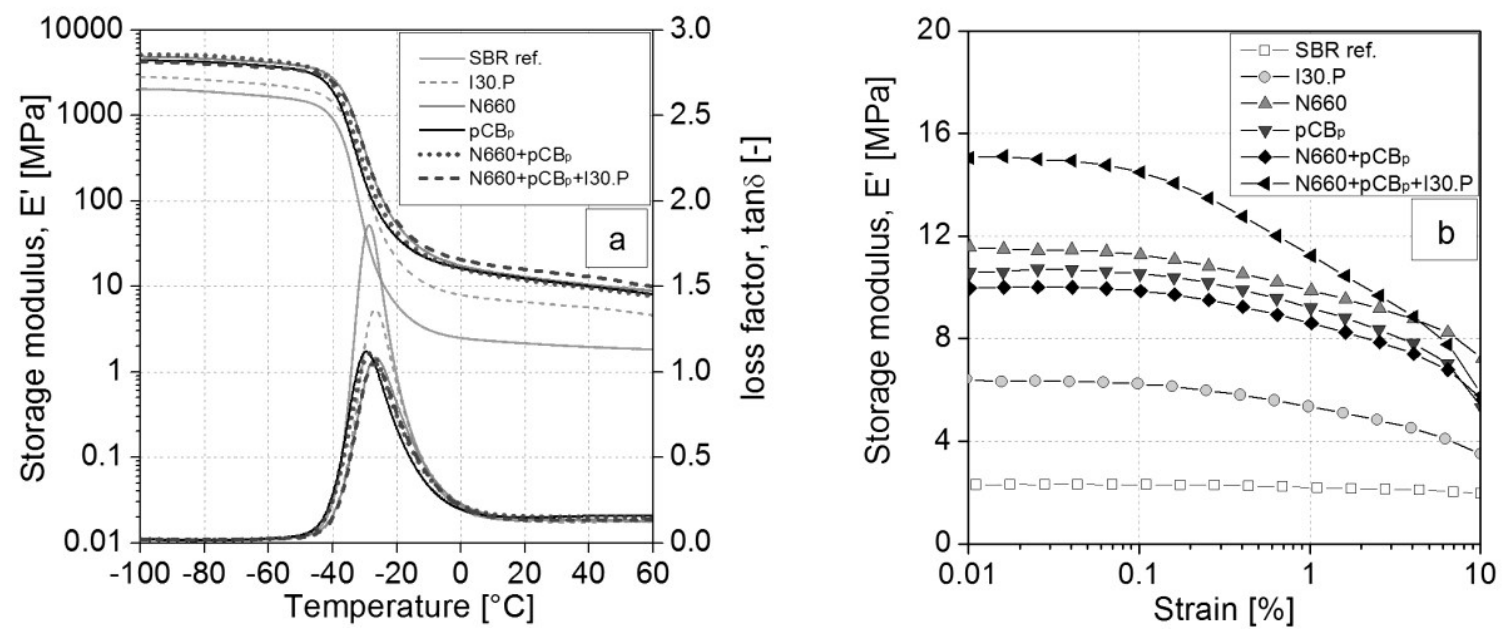

Figure 2. Dynamic mechanical thermal properties, DMTA results of the SBR rubbers:

a.) Storage modulus (E') and mechanical loss factor $(\tan \delta)$ as a function of temperature;

b.) E' as a function of strain (Payne effect)

In Figure 3 we illustrate the Mullins effect schematically and also the way, how this has been considered in this work. The Mullins effect has been quantified by considering the force ratio of the cyclic and separate monotonic loading of the specimens at a given strain as a function of the loading cycles. Change in the dissipated energy $\left(E_{\text {diss }}\right)$ has been considered in a similar way, i.e. the hysteresis was related to the overall energy introduced. The corresponding data are listed in Table 2. The values are quite similar for the CB containing samples. As expected, the Mullin's effect becomes more prominent with increasing load level. Furthermore, the largest softening occurred in the first cycle. It seems to I30.P slightly increased the Mullins-effect.

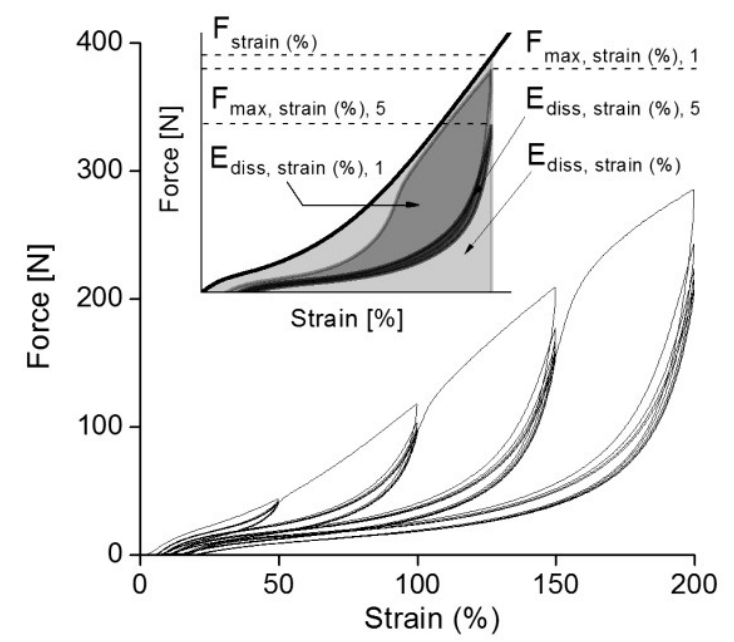

Figure 3. A typical Mullins behavior and its quantification schematically 
Table 2. Mullins effect for the filled SBR rubbers. Mullins effect is quantified by $F_{\max }$, strain (\%), cycle (number) and $\mathrm{E}_{\text {diss, strain (\%), cycle (number) }}$

\begin{tabular}{|l|c|c|c|c|c|c|c|c|}
\hline \multirow{2}{*}{ Designation } & \multicolumn{7}{|c|}{ Mullins-effect [\%] } \\
\cline { 2 - 9 } & $\mathrm{F}_{\max , 50,1}$ & $\mathrm{~F}_{\max , 50,5}$ & $\mathrm{~F}_{\max , 150,1}$ & $\mathrm{~F}_{\max , 150,5}$ & $\mathrm{E}_{\text {diss, } 50,1}$ & $\mathrm{E}_{\text {diss, } 50,5}$ & $\mathrm{E}_{\text {diss, } 150,1}$ & $\mathrm{E}_{\text {diss, }, 150,5}$ \\
\hline SBR ref. & $85 \pm 1$ & $83 \pm 1$ & $92 \pm 2$ & $90 \pm 2$ & $8 \pm 2$ & $6 \pm 2$ & $6 \pm 1$ & $5 \pm 1$ \\
\hline I30.P & $93 \pm 3$ & $87 \pm 3$ & $97 \pm 2$ & $91 \pm 2$ & $16 \pm 1$ & $9 \pm 2$ & $20 \pm 0$ & $10 \pm 1$ \\
\hline N660 & $92 \pm 5$ & $90 \pm 5$ & $97 \pm 6$ & $92+4$ & $20 \pm 2$ & $13 \pm 2$ & $35 \pm 3$ & $14 \pm 1$ \\
\hline pCB $_{\mathrm{p}}$ & $93 \pm 2$ & $88 \pm 2$ & $95+3$ & $85 \pm 3$ & $19 \pm 1$ & $12 \pm 0$ & $34 \pm 1$ & $12 \pm 0$ \\
\hline N660+pCBp & $88 \pm 3$ & $83 \pm 3$ & $95 \pm 4$ & $83 \pm 3$ & $18 \pm 3$ & $11 \pm 2$ & $24 \pm 1$ & $10 \pm 1$ \\
\hline N660+pCBp+I30.P & $86 \pm 2$ & $81 \pm 1$ & $91 \pm 1$ & $81 \pm 1$ & $17 \pm 1$ & $12 \pm 0$ & $25 \pm 0$ & $11 \pm 0$ \\
\hline
\end{tabular}

Fracture mechanical results J-integral values were calculated by Eq. 2, where $\eta$ is an geometric factor with the value of $0.9, \mathrm{~B}$ is the thickness, of test piece, $\mathrm{W}$ the width of the test piece, $\mathrm{a}_{0}$ the initial notch length, $U$ is the area under the measured curve.

$$
J=\frac{\eta \cdot U}{B \cdot\left(W-a_{0}\right)}
$$

As critical $\mathrm{J}$-integral $\left(\mathrm{J}_{\mathrm{c}}\right)$, traced to crack onset, the $\mathrm{J}$-integral value at $\mathrm{CTOD}=0.5 \mathrm{~mm}$ has been considered. It can de stated that the cyclic preloading markedly reduced the above $\mathrm{J}_{\mathrm{c}}$ data confirming effect of Mullins strain softening. For the SBRs with $\mathrm{N}_{6} 60+\mathrm{pCB}$ and $\mathrm{N} 660+\mathrm{pCB}+\mathrm{I} 30 . \mathrm{P}$ a synergistic effect can be seen. It is hypothesized that an efficient stress redistribution via the fillers' dispersion occurs during crack blunting and crack onset whereby the material's resistance is enhanced.

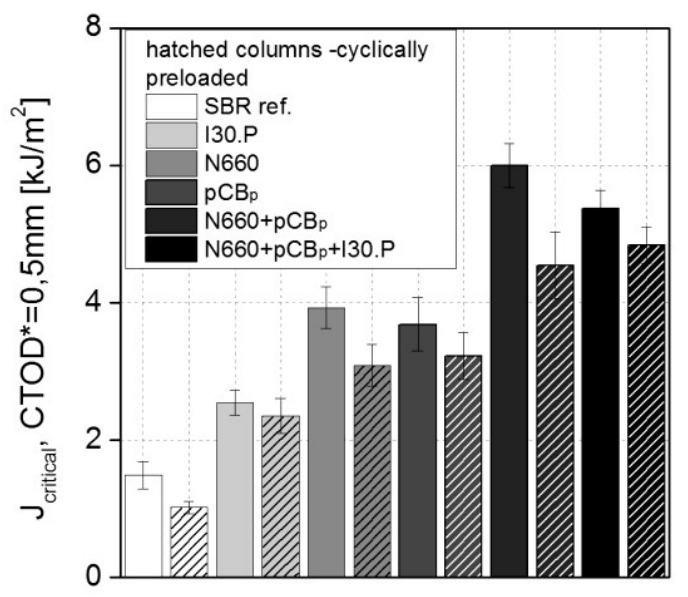

Figure 4. $\mathrm{J}_{\text {critical }}$ values determined at $\mathrm{CTOD}^{*}=0.5 \mathrm{~mm}$

\section{Conclusion}

In this work the tensile mechanical and fracture mechanical behaviors of SBR gums having the same Shore A hardness and filled with industrial $\mathrm{CB}$, pelletized pyrolytic $\mathrm{CB}\left(\mathrm{pCB}_{\mathrm{p}}\right)$ and organoclay in various combinations were determined. The results can be summarized as follow.

N660 yielded higher tensile strength and lower elongation at break than $\mathrm{pCB}_{\mathrm{p}}$ confirming its higher reinforcing activity. On the other hand, the tear strength with $\mathrm{pCB}_{\mathrm{p}}$, even when combined with N660, was higher than with CB alone. This was attributed to a favorable effect of the dispersion (in macro-, micro-, nanoscale). Organoclay may improve the tensile mechanical properties, but has no impact on the tear and trouser strengths, of CB filled SBR mixes. DMTA results showed that introduction of organoclay increased the E' value in rubbery range. Consequently, the Payne-effect become also stronger. Synergistic effect with respect to crack initiation $\left(J_{c}\right)$ was observed for 
$\mathrm{N} 660+\mathrm{pCB} \mathrm{p}_{\mathrm{p}}$ mixture. It was traced to effects of the fillers' dispersion supporting an efficient stress transfer/relieve locally thereby enlarging the related damage zone. Related data on SBR with $\mathrm{N} 660+\mathrm{pCB}+\mathrm{I} 30 . \mathrm{P}$ supported this hypothesis. $\mathrm{J}_{\text {trouser }}$ agreed with the tear strength suggesting that even under mode III-type loading mode I, i.e. crack opening, conditions prevail. $\mathrm{J}_{\mathrm{c}}$ values of the cyclically preloaded specimens were lower than those of the virgin ones. This underlines the importance of Mullins-effect on the fracture mechanical parameters.

\section{References}

[1] Martínez, J. D.; Puy, N.; Murillo, R.; García, T.; Navarro, M. V.; Mastral, A. M. Waste tyre pyrolysis - A review. Renew. Sust. Energy Rev., 2013, 23, 179-213.

[2] Karger-Kocsis, J.; Mészáros, L.; Bárány, T. Ground tyre rubber (GTR) in thermoplastics, thermosets, and rubbers. J. Mater. Sci., 2013, 48, 1-38.

[3] Garcia, P. S.; de Sousa, F. D. B.; de Lima, J. A.; Cruz, S. A.; Scuracchio, C. H. Devulcanization of ground tire rubber: Physical and chemical changes after different microwave exposure times. Express Polym. Lett., 2015, 9, 1015-1026.

[4] Williams, P. T. Pyrolysis of waste tyres: A review. Waste Manag., 2013, 33, 1714-1728.

[5] Karabork, F.; Tipirdamaz, S. T. Influence of pyrolytic carbon black and pyrolytic oil made from used tires on the curing and (dynamic) mechanical properties of natural rubber (NR)/styrene-butadiene rubber (SBR) blends. Express Polym. Lett., 2016, 10, 72-82.

[6] Norris, C. J.; Hale, M.; Bennett, M. Pyrolytic carbon: factors controlling in-rubber performance. Plast. Rubb. Compos., 2014, 43, 245-256.

[7] Delchev, N.; Malinova, P.; Mihaylov, M.; Dishovsky, N. Effect of the modified solid product from waste tyres pyrolysis on the properties of styrene-butadiene rubber based composites. J. Chem. Technol. Metallurgy, 2014, 49, 525-534.

[8] Teh, P. L.; Mohd Ishak, Z. A.; Hashim, A. S.; Karger-Kocsis, J.; Ishiaku, U. S. On the potential of organoclay with respect to conventional fillers (carbon black, silica) for epoxidized rubber compatibilized natural rubber vulcanizates. J. Appl. Polym. Sci., 2004, 94, 2438-2445.

[9] Galimberti, M. Ed., Rubber-Clay Nanocomposites, Wiley:Hoboken, 2011.

[10]Padenko, E.; Berki, P.; Wetzel, B.; Karger-Kocsis, J. Mechanical and abrasion wear properties of hydrogenated nitrile butadiene rubber of identical hardness filled with carbon black and silica. J. Reinf. Plast. Compos., 2016, 35, 81-91.

[11]Heinrich, G.; Vilgis, T. A. A statistical mechanical approach to the Payne effect in filled rubbers. Express Polym. Lett., 2015, 9, 291-299.

[12]Agnelli S.; Ramorino, G.;. Passera, S.; Karger-Kocsis, J.; Ricco, T. Fracture resistance of rubbers with MWCNT, organoclay, silica and carbon black fillers as assessed by the J-integral: Effects of rubber type and filler concentration. Express Polym. Lett., 2012, 6, 581-587. 